\title{
EDITORIAL EX ORIENTE LUX
}

Oh, East is East, and West is West, and never the twain shall meet, Till Earth and Sky stand presently at God's great Judgment Seat;

But there is neither East nor West, Border, nor Breed, nor Birth, When two strong men stand face to face, though they come from the ends of the earth!

(Rudyard Kipling, The Ballad of East and West, 1889)

Ex oriente lux, "la luz viene de oriente», es una locución latina célebre con la que los romanos saludaban la aparición del sol por el horizonte de levante, y que, más allá de su significado astronómico, representa la enorme importancia de Oriente en la génesis de las civilizaciones occidentales. Oriente sigue aún hoy simbolizando una sabiduría y espiritualidad en la que se funden lo nuevo y lo viejo.

Heródoto de Halicarnaso, a quien en cierto modo podemos considerar padre de la Historia, al menos en el mundo occidental, ya plantea al inicio de su obra que las guerras médicas entre Grecia y Persia eran sino un eslabón más en una larga cadena de rivalidad entre Europa y Asia, entre Occidente y Oriente. Esta rivalidad se habría originado a partir del rapto de princesas por ambas partes. Según el historiador griego, que dice seguir fuentes persas, los fenicios, durante una misión comercial, raptaron a la princesa argiva lo, conduciéndola a Egipto. Los griegos, posiblemente cretenses, se vengarían recalando en Tiro y raptando a Europa, hija del rey. A continuación, los griegos llegarían a Ea, en la Cólquide, donde raptarían a la princesa Medea. Una generación después, Alejandro, hijo de Príamo, raptaría a la griega Helena, provocando la guerra de Troya, origen de la enemistad entre griegos y persas.

Todo este pasado histórico-mítico sería asumido con el tiempo por los romanos, quienes, dentro del contexto de esta tensión entre Oriente y Occidente, se harán herederos del linaje troyano, de cuya destrucción por los griegos lograría huir el héroe Eneas, asentándose en la costa de la península itálica y dando lugar a 
una estirpe de la que descenderían los fundadores de Roma. Se justificaría de este modo la propia revancha de Roma sobre Grecia, legitimando su conquista militar, a la vez que se asumiría la herencia cultural griega. Graecia capta ferum victorem cepit, escribiría Horacio (Grecia, conquistada, conquistó a su feroz vencedor); no en vano la traducción de la Odisea por Livio Andrónico sería la primera gran obra épica escrita en latín. Es difícil no ver la huella de Homero en Virgilio, la de Aristófanes en Plauto, la de Tucídides en Tácito o la de Safo en Catulo.

El mito de Eneas permitirá explicar también la rivalidad con Cartago (fundada por fenicios prevenientes de oriente), por el resentimiento causado al abandonar a la reina Dido, quien morirá de forma trágica, suicidándose con la espada de su amante sobre la pira instalada para quemar las pertenencias de este.

Roma, vencedora de las guerras púnicas y de las guerras macedónicas, dominaría el Mediterráneo y se convertirá en el centro de la Ecúmene, del mundo civilizado grecorromano, mirando, como el dios Jano, tanto hacia Oriente como a Occidente, asimilando a unos y a otros. No faltarían las tensiones entre quienes admiraban el mundo oriental de la Grecia democrática y quienes tratarían de imitar a los grandes reyes helenísticos.

En el ámbito religioso también se producirá un sincretismo, acogiendo y asimilando dioses de los diferentes territorios conquistados. Con el tiempo, los cultos orientales ganarían fuerza hasta que uno de ellos, el cristianismo, destacase sobre el resto y acabase, no sin dificultades, imponiendo su dominio sobre el resto.

Tras la división del Imperio romano en Oriental y Occidental, el cristianismo se mantendría como la religión legitimadora del poder en ambos territorios durante un milenio, con sus tensiones y conflictos con una nueva religión, el islam. El choque entre cristianismo e islam provocará grandes enfrentamientos, pero también habrá enormes influencias culturales de todo tipo, permitiéndose la transmisión y reelaboración del pasado grecolatino. Frente a una cierta imagen ampliamente difundida de una Edad Media prácticamente estática, lo que encontramos a lo largo de estos siglos son amplias redes de intercambio, gran movilidad a través de los mercados, importantes rutas de peregrinación, procesos de colonización y repoblación vinculados a un enorme crecimiento demográfico y a una expansión del mundo urbano. Se producirá una gran circulación de intelectuales tras la creación de las primeras universidades. Por supuesto, las guerras también provocarán desplazamientos, tanto de soldados, como de refugiados, que traerán consigo su cultura, su arte y sus historias. La Edad Media fue una época de viajeros como el judío Benjamín de Tudela, el cristiano Marco Polo o el musulmán Ibn Battuta.

La caída del último vestigio del Imperio romano de Oriente, con la conquista de Constantinopla por los turcos otomanos, marcaría el final de la Edad Media. Por otro lado, también en el siglo XV, se produciría el descubrimiento de un nuevo mundo en Occidente, hallado en el intento de encontrar una ruta alternativa hacia Oriente. El mundo se hará más grande, pero comenzará a estar más conectado. 
Surgirían entonces los primeros imperios globales, con capacidad de injerir en la soberanía de varios territorios no conectados geográficamente. Será la época no solo de los grandes imperios territoriales, sino de los grandes imperios comerciales que mirarían hacia Oriente y hacia Occidente a través de sus Compañías de Indias. Será la época del colonialismo, pero también de grandes avances científicos y tecnológicos y de importantes intercambios culturales. La admiración por el pasado grecolatino dialogaría con una renovada pasión por lo oriental, por el exotismo, que será aún mayor en la época contemporánea, pues, tras las revoluciones que supusieron el final de la Edad Moderna, los contactos serán cada vez más estrechos y complejos. Coexistirá, de modo paradójico, la idea de la igualdad entre los seres humanos con la expansión de los imperialismos.

El desarrollo científico, tecnológico y cultural se acelerará enormemente, pero también los conflictos, que alcanzarán una dimensión planetaria, estando el siglo XX marcado por las Guerras Mundiales y por la Guerra Fría, que afectarán a todo el globo.

La conexión será ya total. El mundo actual es un mundo globalizado gracias a las nuevas tecnologías. Las ideas, las personas y los productos viajan a velocidades difícilmente imaginables en las centurias anteriores, lo que hace más necesario si cabe el diálogo entre las culturas, un diálogo que solo puede estar basado en el respeto y el conocimiento.

Los primeros versos del poema de Kipling con el que abrimos este editorial, "La balada del este y el oste», han sido utilizados hasta la saciedad de manera descontextualizada para mostrar que el desencuentro entre Oriente y Occidente es inevitable: "Oh, Oriente es Oriente y el Occidente es Occidente, y los dos no se encontrarán nunca, / hasta que la Tierra y el Cielo estén presentes en el gran Trono del Juicio de Dios». Pero estos dos versos no deberían citarse aisladamente, pues los dos siguientes cambian rotundamente el significado del poema: «iPero no hay ni Oriente ni Occidente, no hay frontera, linaje, ni cuna / cuando dos hombres fuertes se plantan cara a cara, aunque vengan de los confines de la tierra!». La balada trata sobre un oficial británico y un ladrón de caballos afgano que acabarán llegando a la amistad a través del respeto por el otro, un respeto que permite borrar las diferencias.

Hoy día, una gran pandemia ha puesto de manifiesto hasta qué punto el mundo está interconectado de manera que los problemas globales solamente pueden solucionarse con respuestas globales. Oriente y Occidente han establecido a lo largo del tiempo relaciones muy complejas, de admiración, fascinación e influencias recíprocas, pero también de recelos, conflicto y violencia.

El mundo actual necesita que las relaciones entre Oriente y Occidente se establezcan desde la cooperación y el diálogo intercultural en un momento en el que la rivalidad, la desconfianza y la discordia pueden tener consecuencias realmente catastróficas para la humanidad. Pues vencer la pandemia no supone solo erradicar 
la enfermedad, sino hacerlo sin que las desigualdades sigan aumentando, sin abandonar a nadie y ello solo es posible teniendo en cuenta que todos formamos parte de la misma ecúmene.

Iván Pérez Miranda

Director de El Futuro del Pasado
María Victoria Álvarez Rodríguez

Coordinadora del Monográfico 